\title{
Effect of the
}

\section{ethinylestradiol/levonorgestrel combined oral contraceptive on the activity of cytochrome P4503A in obese women}

\section{Correspondence}

Dr Ganesh Cherala PhD, Department of Pharmacy Practice, College of Pharmacy, Oregon State University/Oregon Health and Science University, 3303 SW Bond Ave, CH12C, Portland, OR 97239, USA.

Tel.: +5034180447

Fax: +5034948797

E-mail:cheralag@ohsu.edu

Keywords

combined oral contraceptives,

cytochrome P4503A, ethinylestradiol, levonorgestrel, obesity, pharmacokinetics

Received

20 November 2011

Accepted

15 January 2012

Accepted Article

Published Online

2 February 2012

${ }^{1}$ Department of Obstetrics and Gynecology, Oregon Health and Science University, Portland, OR, ${ }^{2}$ Department of Pharmacy Practice, College of Pharmacy, Oregon State University/Oregon Health and Science University, Portland, OR and ${ }^{3}$ Department of Physiology and Pharmacology, School of Medicine, Oregon Health and Science University, Portland, OR, USA

\section{WHAT IS ALREADY KNOWN ABOUT} THIS SUBJECT

- Obesity is known to suppress CYP3A4/5 activity.

- Use of combined oral contraceptives (COC) has been shown to suppress CYP3A4/5 activity in non-obese women.

- However, the effect of COC on CYP3A4/5 activity is unknown in obese women who constitute $50 \%$ of women of reproductive age.

\section{WHAT THIS STUDY ADDS}

- Although we hypothesized that obesity exposure might amplify the impact on CYP3A4/5 activity in COC users, we found that this was not the case.

- This finding is reassuring regarding potential additional drug-drug interactions in obese COC users as CYP3A4/5 is a major player in the metabolism of many marketed drugs.

\section{AIM(S)}

While it is known that CYP3A4/5 activity is decreased with combined oral contraceptive (COC) use and obesity suppresses CYP expression, the combined effects of obesity and COC use on CYP3A4/5 activity are unclear. Therefore, our aim was to examine the effect of $\mathrm{COC}$ usage on CYP3A4/5 activity in obese women.

\section{METHODS}

Thirty-four, obese (body mass index, BMI $>30 \mathrm{~kg} \mathrm{~m}^{-2}$ ) women of reproductive age (18-35 years old) were placed on a COC pill containing $20 \mu \mathrm{g}$ ethinylestradiol/100 $\mu \mathrm{g}$ levonorgestrel for 21 days starting at the onset of menses. A midazolam pharmacokinetic study was conducted prior to initiation and after 21 days of COC treatment. Serial blood samples were collected and plasma concentrations of midazolam were measured using liquid chromatography tandem mass spectrometry. Pharmacokinetic parameters were estimated using a non-compartmental method.

\section{RESULTS}

Midazolam clearance, a surrogate measure of CYP3A4/5 activity, was significantly decreased upon COC use $\left(63.3 \mathrm{I} \mathrm{h}^{-1} \mathrm{vs} .53 .9 \mathrm{I} \mathrm{h}^{-1}, P<0.05\right)$. A median decrease of $5.6 \mathrm{I} \mathrm{h}^{-1}\left(95 \% \mathrm{Cl}-4.1,13.3 \mathrm{I} \mathrm{h}^{-1}\right)$ was observed. However, the magnitude of change was similar to that reported in women with normal BMI.

\section{CONCLUSIONS}

Although we hypothesized that obesity might amplify the impact on CYP3A4/5 activity in COC users, we found that this was not the case. This finding is reassuring regarding potential additional drug-drug interactions in obese COC users as CYP3A4/5 is a major enzyme in the metabolism of many marketed drugs. 


\section{Introduction}

Combined oral contraceptives (COC) have been in use for about 50 years and are one of the most popular forms of contraception worldwide [1]. COCs are comprised of a synthetic estrogen and progestin. Ethinylestradiol (EE) is the most common estrogenic component but there are a number of different progestin types with levonorgestrel (LNG) dominating the market [2-4].

Both LNG and EE undergo metabolism resulting in plasma concentrations that fluctuate based on the activity of various drug metabolizing enzymes [5, 6]. However, COCs also affect these enzymes [7-10]. In vitro, EE demonstrates inhibition of both phase I and phase II metabolizing enzymes including a major cytochrome P450 (CYP) enzyme, CYP3A4/5 $[9,10]$. The effect of LNG on CYP3A activity is less clear as reports are conflicting $[7,8]$. This close interaction between COCs and drug metabolizing enzymes makes the pharmacokinetics (PK) and subsequent pharmacotherapy of COCs vulnerable to other factors that influence drug metabolism [6].

Obesity, a low grade chronic inflammatory condition [11], is known to suppress the expression of CYP3A4/5 activity [12]. Research has demonstrated altered PK of midazolam, a known marker for CYP3A4/5 activity, in obese subjects [13]. The interaction of obesity and COC exposure on the CYP pathway is unknown but critically important as impaired $\mathrm{COC}$ therapeutics could result in an unplanned pregnancy, a potentially devastating event for this already high risk population [1, 14]. As obese women constitute $50 \%$ of the population of reproductive age [15, $16]$ and COCs are widely used in these women for their contraceptive and non-contraceptive benefits $[17,18]$, the potential public health impact is significant. Additionally, the interaction of obesity and $\mathrm{COC}$ use could compromise the pharmacotherapy of co-administered drugs as a result of $\mathrm{COC}$ induced drug-drug interactions. Our objective was to examine the in vivo activity of CYP3A4/5 using midazolam as a probe for CYP3A4/5 in obese users of COC containing LNG, the most widely used progesterone.

\section{Methods}

\section{Study subjects}

A randomized, prospective study was conducted at the Oregon Health and Science University (OHSU) in Portland, OR. The OHSU Institutional Review Board approved the study protocol and all subjects gave written informed consent.

Thirty-four, obese (body mass index, BMI $>30 \mathrm{~kg} \mathrm{~m}^{-2}$ ) women of reproductive age (18-35 years old), not currently using hormonal contraception but seeking to initiate $\mathrm{COC}$ use, were recruited. Additional eligibility criteria included demonstration of regular menstrual cycles with proven ovulation (luteal phase progesterone $\geq 3 \mathrm{ng} \mathrm{ml}^{-1}$ ), not actively seeking weight gain or loss, no evidence of anaemia (haematocrit $\geq 36 \%$ ), no contraindications to hormonal contraception, no use of tobacco or drugs known to interfere with the metabolism of sex steroids and no overt clinical features of or prior treatment for metabolic disorders (i.e. polycystic ovarian syndrome).

All study subjects were placed on a combination monophasic oral contraceptive pill containing $20 \mu \mathrm{g}$ $\mathrm{EE} / 100 \mu \mathrm{g}$ LNG (Alesse, Wyeth, Madison, NJ, USA) at the onset of menses following the pretreatment cycle. The medication was dosed in a cyclical fashion (21 days active pill with a 7 day hormone-free interval). Women were instructed to take the pill at $09.00 \mathrm{~h}$ daily. Self-reported compliance with the medication was recorded on a calendar, and women were asked to contact investigators if there was a delay in time of pill ingestion and/or two or more missed pills in one cycle. Two or more delayed and/ or missed pills prompted study withdrawal (women were not informed of this consequence but were educated regarding the importance of compliance).

\section{Study design}

Subjects were admitted to the Oregon Health and Science University's Oregon Clinical and Translational Research Institute to collect blood samples for determining PK data prior to initiation and after 21 days of COC treatment. Venous blood samples were collected at 15 and $30 \mathrm{~min}$ and $1,2,4,5,6,12$ and $24 \mathrm{~h}$ following $2 \mathrm{mg}$ midazolam orally. Plasma was isolated and stored at $-80^{\circ} \mathrm{C}$ for long term storage prior to analysis.

Plasma concentrations of midazolam were measured using liquid chromatography tandem mass spectrometry (LC/MS/MS). Briefly, midazolam was extracted from plasma samples $(0.1 \mathrm{ml})$ with $t$-butylmethylether $(5 \mathrm{ml})$ after addition of $0.5 \mathrm{ng} \mathrm{d} \mathrm{d}_{4}$-midazolam as internal standard as described by Hebert et al. [19]. Dried extracts were resuspended and analyzed by LC/MS/MS using electrospray ionization in the positive mode using a modified method of Zhang et al. [20] with a Kinetex C18 column $(2.6 \mu, 100 \AA 50$ $\times 2.1 \mathrm{~mm}$ ) and a Javelin Betabasic C18 guard column. The mobile phase consisted of $20 \mathrm{~mm}$ ammonium formate/ $0.1 \%$ formic acid and methanol with $20 \mathrm{~mm}$ ammonium formate/ $0.1 \%$ formic acid $(25: 75)$ at a flow rate of $0.3 \mathrm{ml} \mathrm{min}{ }^{-1}$. The total run time was $10 \mathrm{~min}$. Midazolam and $\mathrm{d}_{4}$-midazolam were monitored using selective reaction monitoring of the mass transitions of $\mathrm{m} / \mathrm{z}=326 \rightarrow 291.2$ and $\mathrm{m} / \mathrm{z}=330 \rightarrow 295.2$, respectively. A Thermo TSQ Quantum with an Accela HPLC system was used for samples with concentrations from 1 to $20 \mathrm{ng} \mathrm{ml}^{-1}$ midazolam and a AB Sciex QTRAP 5500 with a Shimadzu Prominence HPLC system was used for samples with concentrations from $0.01-1 \mathrm{ng} \mathrm{ml}^{-1}$. Calibration curves were generated by spiking naïve plasma with $0.5 \mathrm{ng}-$ $20 \mathrm{ng} \mathrm{ml}^{-1}$ midazolam for the TSQ instrument and $0.1 \mathrm{ng}-$ $5 \mathrm{ng} \mathrm{ml}^{-1}$ for the QTRAP 5500. Least squares linear regression of the peak area ratio (midazolam normalized to 
$\mathrm{d}_{4}$-midazolam) vs. concentration of midazolam was used for quantification. Slopes of the standard curves varied by $<10 \%$ over 22 different runs with the TSQ Quantum and $<5 \%$ with five different runs with the QTRAP 5500.

The assay limit of detection was $0.01 \mathrm{ng} \mathrm{ml}^{-1}$. The accuracy of lower $\left(0.05 \mathrm{ng} \mathrm{ml}^{-1}\right)$ and upper $\left(20 \mathrm{ng} \mathrm{ml}^{-1}\right)$ limits of quantitation was $90 \%$ and $99 \%$, respectively. The precision of lower and upper limits of quantitation was $13.7 \%$ and $1 \%$ relative SD $(n=12)$, respectively.

\section{Pharmacokinetic analysis}

Midazolam PK data were analyzed by non-compartmental methods using WinNonLin (v 5.2; Pharsight, Mountain View, CA, USA).

\section{Statistical analysis}

Demographic data were analyzed using descriptive statistics. Wilcoxon signed-rank test $(\alpha=0.05)$ was used to assess statistical differences in the pre and post treatment PK

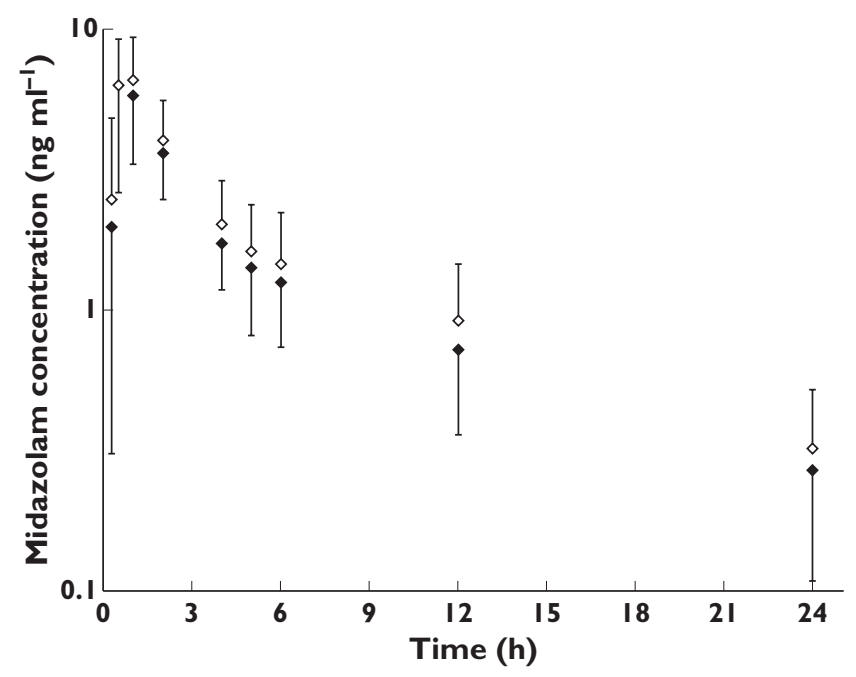

\section{Figure 1}

Pharmacokinetic profile of midazolam before $(\diamond)$ and after $(\diamond)$ COC treatment. Each data point represents mean of 34 subjects with one sided error bar indicating 1 SD parameters of midazolam using SigmaPlot software ( $\mathrm{v}$ 11.0; Systat Software, Inc., San Jose, CA).

\section{Results}

All 34 recruited women completed the study. Thirty of them were non-hispanic, Caucasians. The mean age of study participants was $29.1 \pm 4.6$ (mean \pm SD) years with a mean BMI of $39.7 \pm 6.8 \mathrm{~kg} \mathrm{~m}^{-2}$.

The plasma concentrations of midazolam were consistently higher after $\mathrm{COC}$ use compared with pre-treatment values (Figure 1). The PK parameters, both estimated and observed, were not normally distributed (Table 1 ). Maximum plasma concentration $\left(C_{\max }\right)$ and time to maximum concentration $\left(t_{\mathrm{max}}\right)$, were not affected by 3 weeks of COC use in these obese women. The elimination half-life $\left(t_{1 / 2}\right)$ was found to be slightly longer after the use of COCs. However, the difference failed to reach statistical significance [median $7.5 \mathrm{~h}(95 \% \mathrm{Cl} 7.0,9.6)$ pre treatment vs. $7.9 \mathrm{~h}(95 \% \mathrm{Cl} 7.4,8.7)$ post treatment]. With COC use, apparent volume of distribution $\left(V_{d}\right)$ and apparent oral clearance $(\mathrm{CL})$ significantly decreased $\left[V_{d}\right.$ median $701 \mathrm{I}(95 \% \mathrm{Cl} 660$, $844)$ to 657 I $(95 \% \mathrm{Cl} 609,812), P<0.05 ; \mathrm{CL}$ median $63.3 \mathrm{I} \mathrm{h}^{-1}$ $(95 \% \mathrm{Cl} 59.7,74.6)$ to $\left.53.9 \mathrm{I} \mathrm{h}^{-1}(95 \% \mathrm{Cl} 53.5,71.7), P<0.05\right]$. Conversely, COC use increased the median $\operatorname{AUC}(0, \infty)$ from $31.6 \mathrm{ng} \mathrm{ml}^{-1} \mathrm{~h}(95 \% \mathrm{Cl} 29.3,37.3)$ to $37.1 \mathrm{ng} \mathrm{ml}^{-1} \mathrm{~h}(95 \% \mathrm{Cl}$ $32.2,42.9), P<0.01$.

\section{Discussion}

We found that COC use in obese individuals affected the PK of midazolam including clearance, a measure of the functional status of CYP3A4/5. The magnitude of difference found in obese $\mathrm{COC}$ users was similar to changes reported in women of normal BMI [21, 22]. Although we hypothesized that obesity might amplify the impact on CYP3A4/5 activity in COC users, we found that this was not the case. This finding is reassuring regarding potential additional drug-drug interactions in obese $\mathrm{COC}$ users as

\section{Table 1}

Pharmacokinetic parameters of midazolam in obese women prior to and after treatment with a combined oral contraceptive containing levonorgestrel and ethinylestradiol

\begin{tabular}{|c|c|c|c|}
\hline PK parameter & Pre treatment & Post treatment & Difference \\
\hline$C_{\max }\left(\mathrm{ng} \mathrm{ml}^{-1}\right)$ & $6.74(6.26,8.30)^{*}$ & $6.68(6.53,8.50)$ & $-0.52(-1.12,0.65)$ \\
\hline$t_{\max }(\mathrm{h})$ & $0.53(0.67,0.97)$ & $1.00(0.71,1.16)$ & $0.00(-0.39,0.16)$ \\
\hline$t_{1 / 2}(h)$ & $7.5(7.0,9.6)$ & $7.9(7.4,8.7)$ & $-0.45(-0.90,1.27)$ \\
\hline$V_{d}(\mathrm{I})$ & $701(660,844)$ & $657(609,812) \dagger$ & $80(-37,119)$ \\
\hline $\mathrm{CL}\left(\mathrm{I} \mathrm{h}^{-1}\right)$ & $63.3(59.7,74.6)$ & $53.9(53.5,71.7) \dagger$ & $5.6(-4.1,13.3)$ \\
\hline $\operatorname{AUC}(0, \infty)\left(\mathrm{ng} \mathrm{ml}^{-1} \mathrm{~h}\right)$ & $31.6(29.3,37.3)$ & $37.1(32.2,42.9) \dagger$ & $-5.2(-8.8,0.2)$ \\
\hline
\end{tabular}

*Median $(95 \% \mathrm{Cl})$. tDenotes a significant difference between pre and post treatment pharmacokinetic parameter. 
CYP3A4/5 is a major enzyme in the metabolism of many marketed drugs.

We employed midazolam clearance as a specific probe for CYP3A4/5 activity. Midazolam is an intermediate extraction drug [23], and therefore the determinants of clearance are (a) intrinsic clearance, (b) the fraction unbound in plasma, and (c) blood flow to the liver. In most studies including the current one, changes in the clearance of midazolam are assumed to be due to alterations in intrinsic clearance of midazolam mostly mediated by CYP3A4/5. The inherent assumption in such a conclusion is that the hepatic blood flow and unbound fraction of midazolam are unaltered. While the lack of haemodynamic effects of COCs has been clearly demonstrated [24], the status of protein binding of midazolam is unclear.

Midazolam is highly (96-98\%) bound to human serum albumin and $\alpha_{1}$-acid glycoprotein [25]. While the effect of COCs on serum albumin concentrations is inconclusive [26-28], the concentrations of other serum proteins including $\alpha_{1}$-acid glycoprotein increase upon exposure to COCs $[27,28]$. Furthermore, it is well known that COCs, especially their estrogen component, greatly increase the serum concentrations of sex hormone binding globulin. However, binding of midazolam to sex hormone binding globulins has not been reported. In addition to the amount of serum proteins, the binding affinity of drugs to the serum proteins plays a vital role in the circulation of the bound or unbound form. The binding of midazolam to albumin was shown, using in vitro incubations, to increase in the presence of a high ionic plasma concentration [29]. The use of COCs has been shown to affect the renal handling of electrolytes [30]. While estrogens promote sodium retention, progestins are known to promote natriuresis. Since COCs have more estrogenic than progestagenic activity [30], it is expected that the combined effect of COCs would be sodium retention leading to an increase in ionic concentration in plasma. The above changes in serum proteins could potentially alter the unbound fraction of a drug, including midazolam.

The volume of distribution of a drug is directly related to plasma volume, tissue volume and fraction unbound in plasma, and inversely related to fraction unbound in tissues. Data on tissue binding is limited due to the inaccessibility of this body compartment. Since the volume of distribution was compared before and after 3 weeks of $\mathrm{COC}$ use in the same obese subjects, not actively looking to lose weight during the study duration, we assumed that the tissue volumes were unchanged over this period. For a highly lipophilic drug like midazolam, the role of plasma volume could be considered to be insignificant. In this study, volume of distribution of midazolam wass slightly, but significantly, decreased ( $7 \%)$ after 3 weeks of COC use. Since there is a direct relationship between volume of distribution and fraction unbound in plasma, we deduced that the unbound fraction of midazolam was also decreased after COC use. Therefore, the change in midazolam clearance after $\mathrm{COC}$ treatment was a cumulative effect of decreased CYP3A4/5 activity and increased protein binding. Though the overall decrease of $\sim 15 \%$ in midazolam clearance was statistically significant, the clinical significance of such a minor alteration is questionable.

The PK of drugs co-administered with COCs has been shown to be altered in many studies [6], although most of the reported drug interactions with COCs are nonCYP3A4/5 mediated $[6,8]$. However, it is unclear if that is true in women with obesity which alters the expression of a host of enzymes including CYP3A4/5 [12,31]. We hypothesized that COCs in the presence of obesity would cause an additive, if not greater, alteration in the activity of CYP3A4/5. The current study findings reveal lack of such an effect in obese women.

\section{Competing Interests}

AE has been a trainer for Merck and received royalties from UpToDate. com. There are no other competing interests to declare.

The authors acknowledge the grant support from National Institutes of Health (R01 HD061582-01 NICHD), the OHSU Oregon Clinical and Translational Research Institute (NIH NCRR 1 UL1 RR024120) and the Bioanalytical Shared Resource/Pharmacokinetics Core at OHSU.

\section{REFERENCES}

1 Trussell J. The cost of unintended pregnancy in the United States. Contraception 2007; 75: 168-70.

2 Dinger J, Minh TD, Buttmann N, Bardenheuer K. Effectiveness of oral contraceptive pills in a large U.S. cohort comparing progestogen and regimen. Obstet Gynecol 2011; 117: 33-40.

3 Farmer RD, Lawrenson R. Utilization patterns of oral contraceptives in UK general practice. Contraception 1996; 53: $211-5$.

4 Seaman HE, de Vries CS, Farmer RD. Differences in the use of combined oral contraceptives amongst women with and without acne. Hum Reprod 2003; 18: 515-21.

5 Stanczyk FZ, Roy S. Metabolism of levonorgestrel, norethindrone, and structurally related contraceptive steroids. Contraception 1990; 42: 67-96.

6 Zhang H, Cui D, Wang B, Han YH, Balimane P, Yang Z, Sinz M, Rodrigues AD. Pharmacokinetic drug interactions involving 17alpha-ethinylestradiol: a new look at an old drug. Clin Pharmacokinet 2007; 46: 133-57.

7 Ellison J, Thomson AJ, Greer IA, Walker ID. Drug points: apparent interaction between warfarin and levonorgestrel used for emergency contraception. BMJ 2000; 321: 1382.

8 Johnson EF, Schwab GE, Vickery LE. Positive effectors of the binding of an active site-directed amino steroid to rabbit cytochrome P-450 3c. J Biol Chem 1988; 263: 17672-7. 
9 Laine K, Yasar U, Widen J, Tybring G. A screening study on the liability of eight different female sex steroids to inhibit CYP2C9, 2C19 and 3A4 activities in human liver microsomes. Pharmacol Toxicol 2003; 93: 77-81.

10 Lin HL, Kent UM, Hollenberg PF. Mechanism-based inactivation of cytochrome P450 3A4 by 17 alpha-ethynylestradiol: evidence for heme destruction and covalent binding to protein. J Pharmacol Exp Ther 2002; 301: 160-7.

11 Heilbronn LK, Campbell LV. Adipose tissue macrophages, low grade inflammation and insulin resistance in human obesity. Curr Pharm Des 2008; 14: 1225-30.

12 Cheng PY, Morgan ET. Hepatic cytochrome P450 regulation in disease states. Curr Drug Metab 2001; 2: 165-83.

13 Greenblatt DJ, Abernethy DR, Locniskar A, Harmatz JS, Limjuco RA, Shader RI. Effect of age, gender, and obesity on midazolam kinetics. Anesthesiology 1984; 61:27-35.

14 Holt VL, Scholes D, Wicklund KG, Cushing-Haugen KL, Daling JR. Body mass index, weight, and oral contraceptive failure risk. Obstet Gynecol 2005; 105: 46-52.

15 Mojtabai R. Body mass index and serum folate in childbearing age women. Eur J Epidemiol 2004; 19: 1029-36.

16 Vahratian A. Prevalence of overweight and obesity among women of childbearing age: results from the 2002 National Survey of Family Growth. Matern Child Health J 2009; 13: 268-73.

17 Trussell J. Understanding contraceptive failure. Best Pract Res Clin Obstet Gynaecol 2009; 23: 199-209.

18 Trussell J, Schwarz EB, Guthrie K. Obesity and oral contraceptive pill failure. Contraception 2009; 79: 334-8.

19 Zhang S, Song N, Li Q, Fan H, Liu C. Liquid chromatography/tandem mass spectrometry method for simultaneous evaluation of activities of five cytochrome P450s using a five-drug cocktail and application to cytochrome P450 phenotyping studies in rats. J Chromatogr B Analyt Technol Biomed Life Sci 2008; 871: 78-89.

20 Hebert MF, Easterling TR, Kirby B, Carr DB, Buchanan ML, Rutherford T, Thummel KE, Fishbein DP, Unadkat JD. Effects of pregnancy on CYP3A and P-glycoprotein activities as measured by disposition of midazolam and digoxin: a University of Washington specialized center of research study. Clin Pharmacol Ther 2008; 84: 248-53.

21 Balogh A, Gessinger S, Svarovsky U, Hippius M, Mellinger U, Klinger G, Hoffmann A, Oettel M. Can oral contraceptive steroids influence the elimination of nifedipine and its primary pryidine metabolite in humans? Eur J Clin Pharmacol 1998; 54: 729-34.

22 Palovaara S, Kivisto KT, Tapanainen P, Manninen P, Neuvonen PJ, Laine K. Effect of an oral contraceptive preparation containing ethinylestradiol and gestodene on CYP3A4 activity as measured by midazolam 1'-hydroxylation. Br J Clin Pharmacol 2000; 50: 333-7.

23 Rogers JF, Rocci ML, Jr, Haughey DB, Bertino JS, Jr. An evaluation of the suitability of intravenous midazolam as an in vivo marker for hepatic cytochrome P4503A activity. Clin Pharmacol Ther 2003; 73: 153-8.

24 Ahmed SB, Kang AK, Burns KD, Kennedy CR, Lai V, Cattran DC, Scholey JW, Miller JA. Effects of oral contraceptive use on the renal and systemic vascular response to angiotensin II infusion. J Am Soc Nephrol 2004; 15: 780-6.

25 Reves JG, Newfield P, Smith LR. Influence of serum protein, serum albumin concentrations and dose on midazolam anaesthesia induction times. Can Anaesth Soc J 1981; 28: 556-60.

26 Carlstrom K, Karlsson R, Von Schoultz B. Diurnal rhythm and effects of oral contraceptives on serum dehydroepiandrosterone sulfate (DHEAS) are related to alterations in serum albumin rather than to changes in adrenocortical steroid secretion. Scand J Clin Lab Invest 2002; 62: 361-8.

27 Horne CH, Weir RJ, Howie PW, Goudie RB. Effect of combined oestrogen-progestogen oral contraceptives on serum levels of alpha 2-macroglobulin, transferrin, albumin and lgG. Lancet 1970; 1: 49-50.

28 Obisesan KA, Adenaike FA, Okunlola MA, Adenaike AA. Effects of oral contraceptives on total serum proteins, albumin, globulins and cholesterol levels in Ibadan, Nigeria. West Afr J Med 2002; 21: 197-9.

29 Khan SN, Islam B, Khan AU. Probing midazolam interaction with human serum albumin and its effect on structural state of protein. Int J Integr Biol 2007; 1: 102-12.

30 Sims ST, Rehrer NJ, Bell ML, Cotter JD. Endogenous and exogenous female sex hormones and renal electrolyte handling: effects of an acute sodium load on plasma volume at rest. J Appl Physiol 2008; 105: 121-7.

31 Abernethy DR, Greenblatt DJ, Divoll M, Smith RB, Shader RI. The influence of obesity on the pharmacokinetics of oral alprazolam and triazolam. Clin Pharmacokinet 1984; 9: 177-83. 